\title{
CORRESPONDENCE.
}

\section{ON THE D AND N FORMULA FOR A TERM ASSURANCE.}

To the Editor of the Journal of the Institute of Actuaries.

SIR,-I have not found in any of our treatises the application of the ordinary Commutation formula, when expressed in terms of Columns $\mathrm{N}$ and $\mathrm{D}$, to term assurances, and would therefore point out its convenience in the computation of foreign rates, those for joint lives and others, the tables for which may be but partially complete.

The annual premium for $n$ years' assurance on $x$ being $\frac{\mathbf{M}_{x}-\mathbf{M}_{x+n}}{\mathbf{N}_{x-1}-\mathbf{N}_{x+n-1}}$ is convertible to $\frac{\mathrm{D}_{x}-\mathrm{D}_{x+n}}{\mathrm{~N}_{x-1}-\mathrm{N}_{x+n-1}}-(1-v)^{*}$; calculation by the second being little more laborious than by the first.

Subject to the following modification, the formula is amenable to the practical application treated of by Mr. Peter Gray in the Journal, vol. x. p. 118.

I. Were the 1 assured made due at the beginning of the first instead of at the end of the last year of the transaction, the equivalent payment for it would be the "term" annuity due which 1 would purchase, say $\frac{D_{x}}{N_{x-1}-N_{x+n-1}}$; but

II, this not being so, from each payment falls to be deducted the difference between 1 and its present value due a year hence, $(1-v)$; and finally,

III, the stipulated 1 not being payable at all should the assured be alive at the end of the term ( $n$ years), the annual premium for such an endowment, $\frac{\mathrm{D}_{x+n}}{\mathrm{~N}_{x-1}-\mathrm{N}_{x+n-1}}$, has likewise to be subtracted from the foregoing, the complete formula being the result.

$$
\begin{gathered}
\text { I am, Sir, } \\
\text { Your most obedient servant, }
\end{gathered}
$$

\section{H. AMBROSE SMITH.}

* This form of expressing such a preminm was one of a number contributed by myself to the Joumal in January 1859 (vol. viii, p. 117), and is referred to now to eorrect a misprint occurring in that communieation. The single preminm for the benefit in question (Example 5) should be

$$
1-\frac{(1-v)\left(\mathrm{N}_{x-1, y-1}-\mathrm{N}_{x+n-1, y+n-1}\right)}{\mathrm{D}_{x, y}} .
$$

2 King William Street, E.C., London, 11 Mareh 1875.

\section{ON THE APPROXIMATE VALUE OF A COMPLETE ANNUTTY PAYABLE BY INSTALMEN'S.}

To the Editor of the Journal of the Institute of Actuaries.

SIR,-In his report on and valuation for the Madras Medical Fund in 1840 , the late Mr. Griffith Davies gave a very simple method for 